\title{
Dual Role of CD4 in Peripheral T Lymphocytes
}

\begin{abstract}
Daniela Glatzová ${ }^{1,2}$ and Marek Cebecauer ${ }^{1 *}$
${ }^{1}$ Department of Biophysical Chemistry, J. Heyrovsky Institute of Physical Chemistry of the Czech Academy of Sciences, Prague, Czechia, ${ }^{2}$ Laboratory of Leukocyte Signaling, Institute of Molecular Genetics of the Czech Academy of Sciences, Prague, Czechia
\end{abstract}

The interaction of T-cell receptors (TCRs) with self- and non-self-peptides in the major histocompatibility complex (MHC) stimulates crucial signaling events, which in turn can activate $T$ lymphocytes. A variety of accessory molecules further modulate T-cell signaling. Of these, the CD4 and CD8 coreceptors make the most critical contributions to T cell sensitivity in vivo. Whereas, CD4 function in T cell development is well-characterized, its role in peripheral $T$ cells remains incompletely understood. It was originally suggested that CD4 stabilizes weak interactions between TCRs and peptides in the $\mathrm{MHC}$ and delivers Lck kinases to that complex. The results of numerous experiments support the latter role, indicating that the CD4-Lck complex accelerates TCR-triggered signaling and controls the availability of the kinase for TCR in the absence of the ligand. On the other hand, extremely low affinity of CD4 for MHC rules out its ability to stabilize the receptor-ligand complex. In this review, we summarize the current knowledge on CD4 in T cells, with a special emphasis on the spatio-temporal organization of early signaling events and the relevance for CD4 function. We further highlight the capacity of CD4 to interact with the $\mathrm{MHC}$ in the absence of TCR. It drives the adhesion of $\mathrm{T}$ cells to the cells that express the MHC. This process is facilitated by the CD4 accumulation in the tips of microvilli on the surface of unstimulated T cells. Based on these observations, we suggest an alternative model of CD4 role in T-cell activation.

\section{Keywords: T lymphocytes, CD4, TCR coreceptor, Lck, cell-cell adhesion, microvilli}

\section{INTRODUCTION}

In vertebrates, $\mathrm{T}$ lymphocytes (also called $\mathrm{T}$ cells) continuously scan tissues for foreign antigens. On the surface of these cells, T-cell receptors (TCRs) recognize the antigens as short peptides bound to the major histocompatibility complex (MHC) on antigen-presenting cells (APCs; Figure 1). Thus, TCR-peptide-MHC (pMHC) pairs determine the specificity of the T cell-dependent immune response. However, several other surface receptors of T cells (e.g., CD2, CD4, CD5, CD8, CD28, and LFA-1) and of APCs (e.g., CD58, CTLA-4, and ICAM-1) can regulate the sensitivity and output of $\mathrm{T}$ cell responses. Of these receptors, CD4 and CD8 most critically contribute to the T cell function in vivo and thus are known as coreceptors of TCR. CD4 and CD8 share ligands with TCRs by binding to invariant segments of the MHC (Figure 1). As discussed below, CD4 and CD8 also contribute to T-cell development, homeostasis and antigenic response. However, the mechanisms behind these activities are not yet fully understood. This is especially true for CD4, which has extremely low affinity for its ligand but which is also essential in T-cell development and in the removal of pathogens during $\mathrm{T}$ cell-dependent immune responses. 


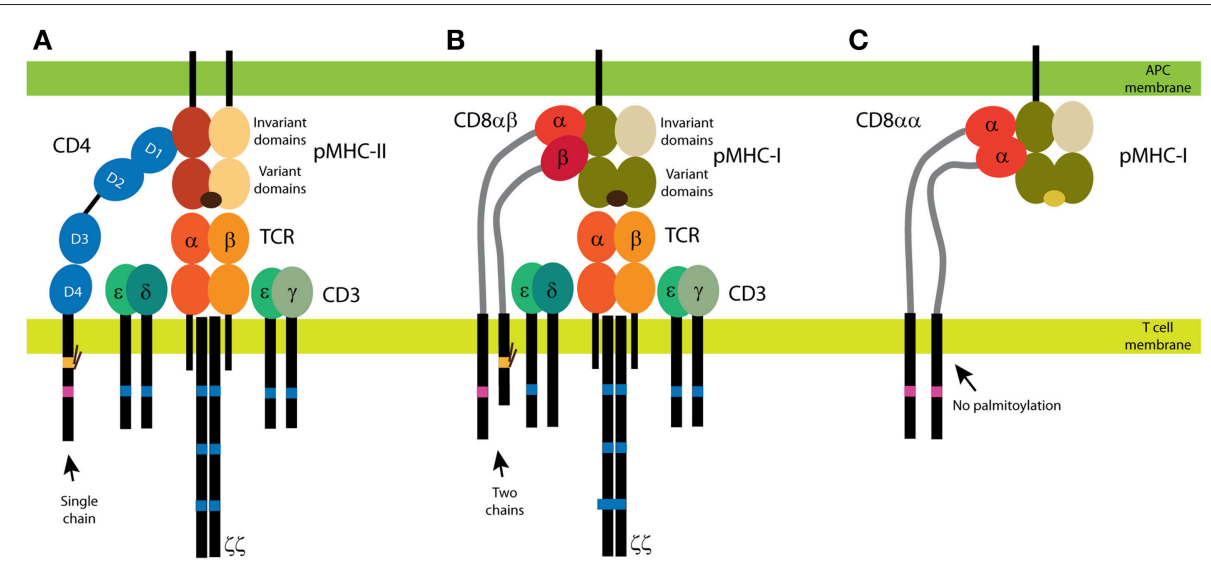

FIGURE 1 | CD4 and CD8 coreceptors. (A) The CD4 glycoprotein is composed of a single chain. Its functional motifs, such as the Lck-binding site (in magenta) and the palmitoylation site (in yellow), are in the sole intracellular domain. The extracellular part of CD4 is composed of four lg-like domains, and the MHC binding site is in the $\mathrm{N}$-terminal D1 domain. Short linker connects CD4 extracellular domains with the transmembrane domain. (B,C) Two forms of CD8 exist: the $\alpha \beta$ heterodimer (B) and the $\alpha \alpha$ homodimer (C). The $\alpha$ subunit of CD8 contains the Lck-binding site, and the $\beta$ subunit contains the palmitoylation site. A single Ig-like domain and a long stalk region (in light gray) form the extracellular parts of the CD8 subunits. Binding of CD4 (A) and CD8 $\alpha \beta$ (B) to MHC is illustrated with the antigenic receptor because these coreceptors support receptor function in T cells. The TCR/CD3 complex is composed of at least eight subunits. CD3 subunits $\gamma, \delta$, and $\varepsilon$ contain one immunoreceptor tyrosine-based activation motif (ITAM; in dark blue) and three ITAMs are in each $\zeta$ subunit. Cognate peptides are depicted in dark brown, self-antigens in light brown.

In this work, we focus on dual role of $\mathrm{CD} 4$ in peripheral $\mathrm{T}$ cells. Contributions of CD4 to antigen-dependent TCR signaling are well-established. However, its antigen-independent function has not been studied in detail. After a brief introduction to the biochemistry of initial events, we focus on providing more indepth insight into the spatio-temporal organization of signaling events in T cells so as to highlight the importance of nanoscopic localization of molecules. In later sections, we present and discuss the accumulated knowledge on function of CD4 in TCR signaling, with an emphasis on spatial organization of CD4 in $\mathrm{T}$ cells. Finally, we describe antigen-independent role of CD4 and speculate on its role in T-cell activation.

\section{T CELLS AND ANTIGEN-INDUCED SIGNALING}

$\mathrm{T}$ cells originate in bone-marrow haematopoietic stem cells. The progenitors of these cells migrate to the thymus, where thymocytes undergo a series of maturation and selection processes to complete the TCR expression and to avoid stimulation by self-antigens. This process, called thymic $\mathrm{T}$ cell development, gives rise to the peripheral pool of T cells, which mainly express $\alpha \beta T C R$. Although $1-10 \%$ of $\mathrm{T}$ cells express $\gamma \delta$ TCR on their surface, these cells recognize nonpeptidic antigens (1). This review focuses on peripheral $\alpha \beta$ $\mathrm{T}$ cells.

TCRs are heterodimers formed by the subunits $\alpha$ and $\beta$, each of which contains two extracellular immunoglobulin (Ig)like domains, a single transmembrane domain and a short intracellular tail that lacks any known structural or functional motif (Figure 1). The $\alpha \beta$ heterodimer forms a complex with the CD3 subunits $(\gamma, \delta, \varepsilon, \zeta)$ for surface expression and full function
(Figure 1). The intracellular tails of CD3 subunits contain immunoreceptor tyrosine-based activation motifs (ITAMs), which are involved in TCR-induced signaling. The TCR/CD3 complex lacks enzymatic activity. This distinguishes TCRs (and other immunoreceptors) from the receptors that directly stimulate downstream events upon binding to a ligand (e.g., receptor kinases).

Based on the current understanding of these processes, it is predicted that the interaction between TCRs and the pMHC is the first step toward antigen-induced T-cell activation. Consequently, early signaling events can be detected when Lck kinase phosphorylates ITAMs in the cytosolic tails of the CD3 subunits that are associated with TCR. Each ITAM contains two phosphorylated tyrosines, which serve as high-affinity docking sites for the tandem SH2 domains of ZAP-70 kinase. Lck also phosphorylates and binds ZAP-70 to induce its full activation (2). As Lck is bound to ZAP-70 via its SH2 domain, its open form provides a docking site (the SH3 domain) for the LAT adaptor protein. This leads to bridging between ZAP-70 and its substrates, LAT and SLP-76 (3). The ZAP-70 phosphorylation of the activating tyrosines on LAT forms a platform for the interactions of LAT with signaling molecules such as SLP-76, Grb2/Sos, PLC $\gamma 1$, and Vav1, and for the formation of a signalosome that regulates the downstream effector events associated with Tcell activation (4). Although the signaling pathways that are downstream of LAT have been thoroughly described, the initial events of the T-cell activation are still incompletely understood (5). Importantly, there is a lack of clarity regarding how and when Lck associates with the TCR-signaling complex. CD4 and CD8 potentially play important roles in this process because, in resting $\mathrm{T}$ cells, a large fraction of Lck is associated with these molecules $(6,7)$. 


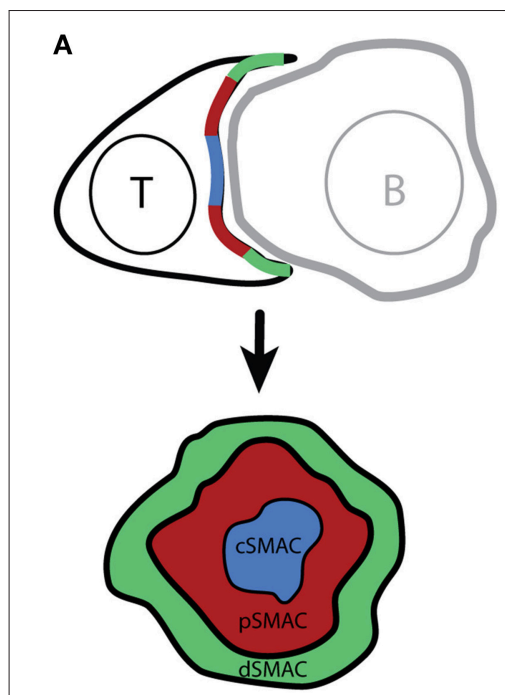

Immunological synapse

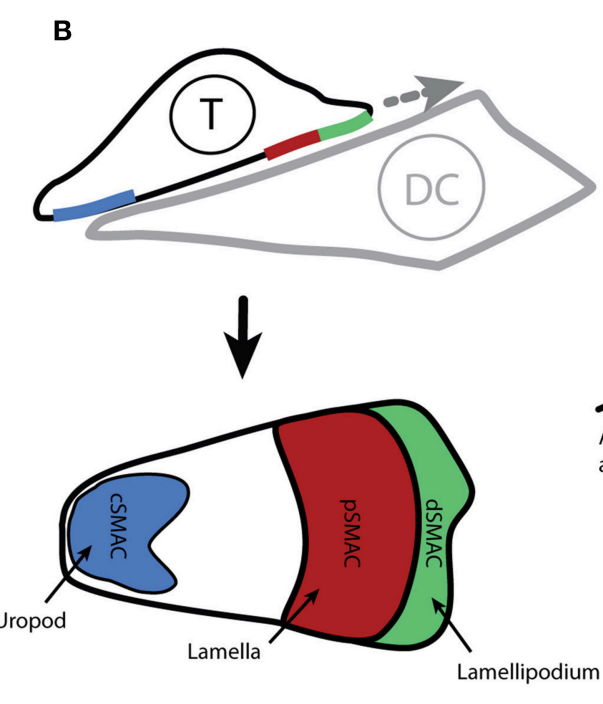

Kinapse

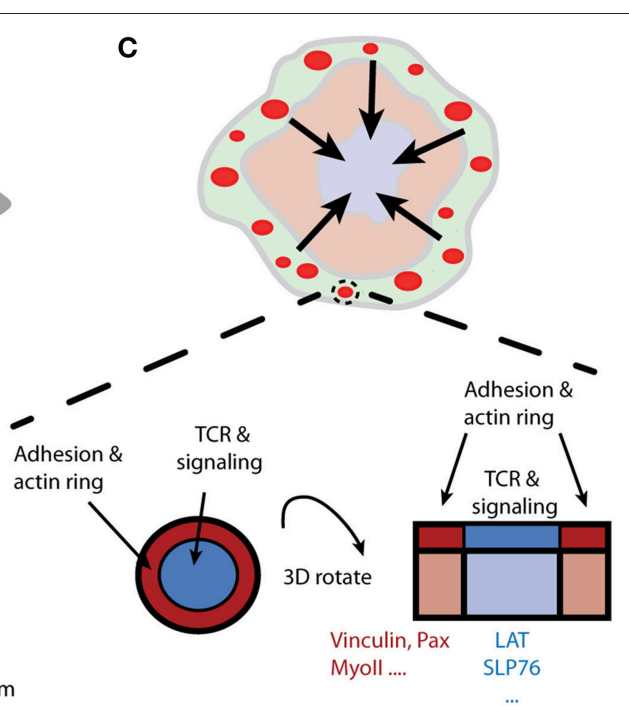

Signaling microclusters

FIGURE 2 | Spatio-temporal organization of T-cell activation. (A) The contact site between T cells and antigen-presenting cells (which form conjugates) is called the immunological synapse due to its similarity to neuronal synapses. Live-cell confocal microscopy reveals the supramolecular organization of molecules within the immunological synapse, with the receptors and effector molecules accumulating in the center of the mature synapse (cSMAC) and adhesion molecules forming a peripheral ring (pSMAC; i.e., the bull's eye model). (B) Motile T cells form asymmetric kinapses instead of stable and symmetric synapses. Kinapses are similar to motile fibroblast cells with lamellipodium (dSMAC), lamella (pSMAC), and uropod (cSMAC). (C) Total internal-reflection fluorescence microscopy reveals that T-cell signaling is initiated in small microclusters that are assembled upon antigenic stimulation in actin-rich distal regions of the immunological synapse (A; dSMAC). Small rings of adhesion molecules and actin surround TCR microclusters and could serve to stabilize those microclusters.

\section{T-CELL ACTIVATION EVENTS: SPATIOTEMPORAL ORGANIZATION}

After recognizing an antigen, $\mathrm{T}$ cells form tight contact with target cells. The instruction to stop the crawling of $\mathrm{T}$ cells comes from the interaction of TCRs with a cognate $\mathrm{pMHC}$. This process, which is called inside-out signaling, enhances integrin affinity for its ligands [e.g., ICAM-1; $(8,9)$ ]. Consequently, a site of extensive contact between T cells and APC forms. The contact site remains dynamic but is also highly organized in time and space. As such sites are reminiscent of the synapses formed between neurons they are named immunological synapses [IS; Figure 2; $(10,11)$ ]. In addition to TCRs and pMHC, diverse stimulatory and inhibitory receptor-ligand pairs, as well as intracellular signaling molecules are localized in the IS during T-cell activation (4).

In the classical model of IS, the TCR receptor and signaling molecules accumulate in the center of a structure that is reminiscent of a bull's eye (Figure 2A). This area is called the central supramolecular activating cluster (cSMAC) and it is surrounded by an adhesive ring (LFA-1/ICAM-1) called a peripheral SMAC (pSMAC). The initial theory was that an IS functions as a stabilizing element, supporting sustained signaling via TCRs (12). Researchers challenged this concept after finding that $\mathrm{T}$ cells often lack a classical IS when conjugated with dendritic cells that are loaded with physiological levels of antigen (13). Several observations indicate that IS result from, rather than being a prerequisite for, T-cell signaling (14-17). It is thus evident that, at least in its early phase, the IS structure must be more dynamic than originally thought; this resulted in the concept of kinapses (18). When forming kinapses (Figure 2B), migrating $\mathrm{T}$ cells decelerate upon stimulation but do not stop to form stable, symmetric synapses. The T-cell leading edge, which is reminiscent of the lamellipodium in motile fibroblasts, forms a structure for TCR signaling initiation, whereas adhesive molecules and a densely branched actin cytoskeleton accumulate in the lamella. Importantly, the signaling and the adhesive molecules are spatially segregated in both modes of the $\mathrm{T}$ cellAPC contact site: synapses and kinapses. Primary T cells mainly form kinapses when interacting with stimulatory cells or surfaces, both in vivo and in vitro $(17,19)$.

Whereas, intravital microscopy confirms the formation of organized contact sites between T cells and APCs in vivo, a better understanding of spatio-temporal organization of signaling events required new microscopy techniques (e.g., total internalreflection fluorescence and super-resolution microscopy) and supported planar bilayers functionalized with activating (pMHC) and adhesive (ICAM-1) molecules (20, 21). Improved imaging conditions enabled the discovery of signaling microclusters. For instance, TCR microclusters are formed in the distal regions of the IS (Figures $\mathbf{2 A}, \mathbf{C}$ ) and represent the sites of signal initiation $(22,23)$. These microclusters are associated with essential signaling components such as Lck, ZAP70 and LAT, but they exclude CD45 phosphatase, which can dephosphorylate ITAMs (2, 15, 23). Interestingly, TCR microclusters are mobile assemblies. In response to strong antigenic stimulation, the microclusters move centripetally from the periphery toward the center of the IS [Figure 2C; $(11,15,22)]$. It is unclear how these structures stabilize 
during movement over several microns. The LFA-1/ICAM-1 micro-adhesive rings that surround microclusters, thus forming micro-synapses, may be a stabilizing factor [Figure 2C; (24)]. Of note, signaling microclusters gave way to nanoclusters due to improvements in microscopes, which provide more appropriate information about the size of these clusters: 100-500 nm (25-27).

The Varma group reported the existence of TCR microclusters in unstimulated $\mathrm{T}$ cells (28) and found that the number of TCR in microclusters remains constant upon stimulation. The LAT and Grb2 signaling molecules are associated with the preexisting clusters, and CD45 is excluded from these structures even before the antigen stimulation (28). These results indicate that TCRs and effector molecules are pre-assembled in structures that are unresolvable using standard light microscopy $[<300 \mathrm{~nm}$; (29)]. Moreover, the data on the molecular organization of TCR microclusters are limited. Some researchers have reported the existence of TCR oligomers on the surface of T cells before antigen stimulation $(30,31)$, but others demonstrated that TCRs have random distribution and a monomeric character during ligand recognition (32-34). TCR assembly in higher-order structures then occurs upon stimulation (34). Importantly, preassembling of the receptor and the effector signaling molecules in higher-order structures could explain the rapid responsiveness of $\mathrm{T}$ cells (35). However, it is not clear whether these models authentically represent the $\mathrm{T}$ cells in the tissues of higher vertebrates. Current imaging technologies do not allow for highresolution imaging of cellular structures in living animals.

\section{T CELL CORECEPTORS}

The previous sections focus on the essential molecules involved in T-cell activation and on descriptions of the morphological and molecular structures which were previously found to contribute to this process. These studies have usually investigated TCRs and downstream signaling molecules; they thus have provided little information about the involvement of coreceptors. The experiments have been often performed using stimulation with anti-CD3 or TCR antibodies, which overpass CD4 and CD8 coreceptors in the initial phase of signaling. Such simulation activates $\mathrm{T}$ cells, as determined by the IL-2 production and increased expression of the CD25 and CD69 activation markers (36).

In vivo, $\mathrm{CD} 4$ and $\mathrm{CD} 8$ are essential for proper $\mathrm{T}$ cell development and thymic selection. These two coreceptors control the MHC specificity of selected thymocytes by limiting availability of Lck for TCR signaling in the absence of the ligand binding $(6,37)$. In peripheral $\mathrm{T}$ cells, the expression of coreceptors is mutually exclusive. $\mathrm{CD} 4^{+} \mathrm{T}$ cells primarily provide help for B lymphocytes and innate immune cells during infections, whereas most $\mathrm{CD} 8^{+} \mathrm{T}$ cells exhibit cytotoxicity toward virally infected or tumor cells. However, this definition is insufficient because the periphery contains many subsets of $\mathrm{T}$ cells with highly specific functions (38). In this review, we focus on general role of CD4 in T-cell activation, irrespective of cell type. We are aware that the coreceptor levels vary in T-cell subsets and that this can affect CD4 function (39). However, there is insufficient data to elaborate on specific function of CD4 in all
Box 1 | The CD4 and CD8 Coreceptors Are Structurally Diverse.

Even though both are called coreceptors, CD4 and CD8 have significantly different expression profiles and structures. CD8 is a dimer that occurs in two forms: the CD8 $\alpha \alpha$ homodimer and the $C D 8 \alpha \beta$ heterodimer (Figure 1). It is predominantly expressed in a subset of T cells, but it can be found in some natural killer and dendritic cells (41-43). Little is known about the function of the CD8 $\alpha \alpha$ homodimer (44). The CD8 $\alpha \beta$ heterodimer supports TCR signaling when stimulated by antigens on MHC class I (45). In the heterodimer, two subunits with two intracellular tails can modulate TCR activity. Each subunit of CD8 also contains a single globular, Ig-like domain in the $\mathrm{N}$-terminus; this domain is linked to the transmembrane domain via a long, flexible stalk. By contrast, CD4 comprises a single chain [Figure 1; (46)]. Its single intracellular part defines all functions in the downstream signaling. Moreover, CD4 extracellular part is composed of four globular, Ig-like domains that are linked to the transmembrane domain only via a few amino-acid residues. Thus, CD4 extracellular part is extended further from the T-cell membrane and exhibits less flexibility, as compared to the extracellular part of CD8. Both CD4 and CD8 coreceptors can be palmitoylated and can bind Lck. In CD8, the palmitoylation site is in the $\beta$ subunit (45), and the Lck-binding site is in the $\alpha$ subunit $(47,48)$. Both motifs are in single cytoplasmic tail of CD4 [Figure 1; (47-49)]. These structural differences indicate that $\mathrm{T}$ cells use the specific properties of CD4 and CD8 to fine-tune their physiological roles.

$\mathrm{CD} 4{ }^{+}$T-cell subsets. Sewell and colleagues reviewed CD8 and its function in T cells (40); please also see the direct comparison of CD4 and CD8 coreceptors in Box 1.

\section{STRUCTURE AND FUNCTION OF CD4}

Extracellular domain of $\mathrm{CD} 4$, which is responsible for the recognition of its ligands, is composed of four globular Ig-like domains (D1-D4; Figure 1). Whereas, the binding site for IL16 is in the membrane-proximal D4 domain, the N-terminal D1 domain binds to a segment of the non-polymorphic $\beta 2$ domain of MHC class II $(50,51)$. Similarly, HIV (gp120) binds to D1 domain of CD4 (52). Important roles of CD4 in the life cycle of the HIV virus and in the activity of IL-16 in immune responses were reviewed recently $(53,54)$. To avoid the complexity of herein discussed processes, we focus on $\mathrm{CD} 4$ interaction with MHCII in the absence of other ligands.

The intracellular part is responsible for $\mathrm{CD} 4$ palmitoylation [residues 419 and 422 in human CD4 according to the UNIPROT numbering; (49)]. This reversible posttranslational modification is supposed to target proteins in lipid microdomains (55). It also contains a basic-rich motif (residues 423-427: sequence RHRRR) and a Lck-binding site (residues 445 and 447). The transmembrane domain of CD4 contains a conserved GGxxG motif, which was reported to mediate the dimerization of membrane proteins (56). However, such effect has not been confirmed for CD4. Rather, the mutation of this motif to GVxxL reduces the capacity of $\mathrm{CD} 4$ to enhance $\mathrm{T}$ cell sensitivity to weak antigens (57). This indicates that the importance of the CD4 transmembrane domain in T-cell activation but the molecular mechanism remains unknown.

The coreceptor CD4 is expressed in a subset of T cells, naturalkiller (NK) cells, monocytes and macrophages. In macrophages and NK cells, CD4 plays a role in differentiation, migration and cytokine expression $(58,59)$. In $\mathrm{T}$ cells, it is involved in 
thymic development and antigen recognition in the periphery (46). Although function of CD4 in the thymus is well-known, its role in the activation of peripheral $\mathrm{T}$ cells remains enigmatic. Originally, two models of $\mathrm{CD} 4$ function in peripheral $\mathrm{T}$ cells were suggested: 1) CD4 stabilizes the ternary complex of pMHC-TCR [Model 1; Figure 3 (46)], and 2) CD4 recruits Lck kinase to the proximity of the TCR/CD3 complex in order to phosphorylate the ITAMs of $\mathrm{CD} 3$ molecules and initiate intracellular signaling during antigen-induced $\mathrm{T}$ cell activation [Model 2;

Figure 3; (46, 60-62)].

The interaction of TCRs with pMHCII is CD4-independent. In some cases, as in the presence of a very strong agonist, this interaction can activate T cells (63). However, CD4 is required for the recognition of most antigens in vivo. The presence of the CD4 coreceptor enhances $\mathrm{T}$ cell sensitivity to antigens by 30- to 100-fold (64-67) and reduces by approximately tenfold the number of antigenic peptides on APCs that are required for sustained TCR signaling (68). Therefore, CD4 is often depicted as a part of the tightly assembled TCR receptor complex, along with agonist pMHCII (Figure 3, Model 1). However, the plasma membrane organization of the CD4-TCR-pMHC assembly remains unknown. In crystallographic studies of the quaternary complex (which comprises the extracellular domains of TCR, pMHCII and CD4), researchers have revealed a V-shaped arch that is created when TCR and CD4 bind simultaneously to the same pMHCII (51). This structure suggests that TCR bound to pMHCII forms one arm of the arch and that CD4 forms the other arm. The CD4-pMHCII contact site appears as the apex of this structure. The geometry of the interacting extracellular domains of pMHCII, TCR and CD4 supports the formation of the quaternary complex (69). However, the lack of the extracellular CD3 domains and other membrane components in the studied complex has led to speculations regarding the CD4TCR-pMHC assembly under the physiological conditions of two interacting cells.

The Davis group suggested an alternative structure known as the "pseudo-dimer" model [Model 1.2 in Figure 3; (70, 71)]. In this model, two TCR-pMHC pairs form a minimal signaling unit and CD4 bridges the two pairs by binding to MHCII, which contains an agonist (antigenic) peptide, as well as by associating with the TCR of the other TCR/MHCII pair, which contains endogenous (self) peptide (71). Importantly, in this model, they attempt to explain extreme sensitivity of $\mathrm{CD} 4^{+} \mathrm{T}$ cells by suggesting that endogenous peptides play a positive role in T-cell activation $(70,71)$. Most pMHCII on the surface of APCs contain peptides that are derived from endogenous proteins. Only very few antigenic peptides can be found on the MHCII of mature APCs $(70,72)$. Therefore, $\mathrm{T}$ cells must detect rare antigens in a sea of endogenous peptides by adjusting the TCR activation unit toward high sensitivity. However, $\mathrm{T}$ cells simultaneously have to distinguish small differences in affinities and/or the kinetics of TCR binding to agonist or self pMHCII (73). Recently, it was found that stimulatory TCR-pMHCII interaction involves numerous catch bonds; no such bonds exist for interactions that do not involve stimulation (74). This observation provides a new explanation for the numerous exceptions to the rule that 3D affinity of TCR for antigenic pMHCII is five- to seven-fold stronger than its affinity for ligands with endogenous peptides.
On the other hand, this finding does not explain how such minor differences in TCR-pMHC binding lead to opposite outputs in T cells. It has been predicted that CD4 would stabilize stimulatory (antigenic) but not homeostatic (self) TCR-pMHC interactions. It remains unclear how a molecule with extremely low $3 \mathrm{D}\left(\mathrm{K}_{\mathrm{d}}\right.$ $>2.5 \mathrm{mM})$ and $2 \mathrm{D}\left(\mathrm{K}_{\mathrm{d}} \sim 4800\right.$ molecules $\left./ \mu \mathrm{m}^{2}\right)$ affinity for MHCII could achieve this, however (75). CD4 has a negligible effect on the TCR-pMHCII interaction $(76,77)$. On the other hand, CD4 forms a rather stable unit with Lck kinase (7), and the TCR/CD3 complex lacks enzymatic activity. Therefore, the signaling capacity and the ability to localize to MHCII-rich areas of the IS must determine CD4 function in T cells.

\section{CD4 IN THE IMMUNOLOGICAL SYNAPSE}

Varying levels of CD4 were reported to accumulate in the IS between $\mathrm{T}$ cells and the APCs that contain agonists (78-80). These discrepancies were probably caused by the employment of different experimental conditions and the sensitivity of applied imaging techniques. CD4 relocalization to IS matches that of TCRs (78) in terms of timing, but CD4 may have faster kinetics (79). Whereas, TCRs and signaling molecules accumulate in the center of the IS upon strong stimulation (Figure 2A), CD4 was found to distribute evenly throughout the IS or preferentially locate to the periphery of the IS [>3 min; (78)]. Importantly, CD4 relocalization to the contact site with MHCII-expressing cells is an antigen-independent process (79). Unlike with TCRs, the presence of antagonist does not prevent CD4 relocalization toward the APC. These results and new observations from Kuhns and colleagues (81) indicate that CD4 moves in T cell membranes independent of TCR/CD3 complex and does not pre-associate with TCR in unstimulated cells.

At the plasma membrane, CD4 is strongly associated with Lck $(7,82)$. Therefore, CD4 localization to the IS results in Lck accumulation therein $(68,83)$. Lck shows a delayed association with the IS in CD4-knockout $\mathrm{T}$ cells, which in turn delays phosphorylation of the Lck activation site (residue $\mathrm{Tyr}_{394}$ in mouse) and reduces CD4-knockout $\mathrm{T}$ cells responsiveness to antigens (83). On the other hand, phosphorylation of activatory tyrosine in Lck is not crucial to T-cell activation because anti-CD $3 \varepsilon$ antibodies do not induce such phosphorylation but can stimulate $\mathrm{T}$ cells $(82,84,85)$. This can be explained by the modest increase in Lck activity (two- to three-fold) upon phosphorylation of the activating tyrosine. CD4 thus delivers the crucial kinase to the site of TCR triggering and enables its full activation to maximize the sensitivity of $\mathrm{T}$ cells toward rare and weak antigens [Model 2 of the CD4 function in T cells - Figure 3; (62)]. Lck kinase activity does not affect CD4 accumulation in the IS because the Src-family kinase inhibitor (PP1) does not prevent localization of CD4 to the contact site with APCs (79).

\section{ANTIGEN-INDEPENDENT ROLE OF CD4 IN T CELLS}

CD4 was originally described as an adhesion molecule that enhances the contact between T cells and APCs $(86,87)$. In their pillar work, Doyle and Strominger found a direct correlation 


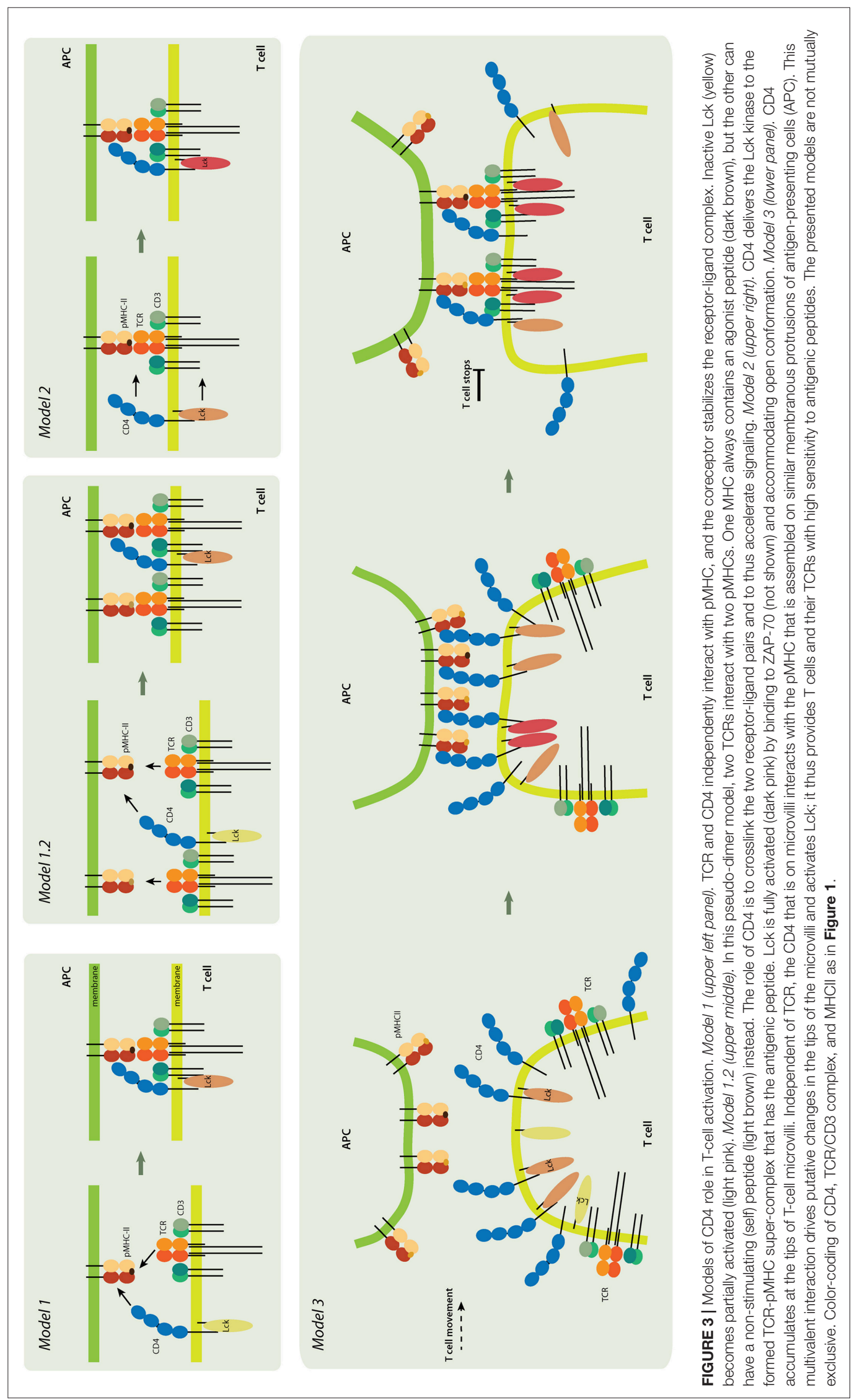


between the extent of cell-to-cell adhesion and the level of MHCII and CD4 expression. Using a monolayer of CD4-expressing fibroblasts and Raji B cell line, which expresses high levels of MHCII, they eliminated the possibility that TCR or other T cellspecific molecules are involved in the interaction (86); observing no adhesion of the cells that did not express MHCII to CD4 ${ }^{+}$ cells, thus confirming the specificity of that interaction. However, using surface plasmon resonance assays, other researchers have shown that CD4 binds the MHCII molecule with an extremely low $3 \mathrm{D}$ affinity [see above; $(75,88)$ ]. This is further supported by the results of $2 \mathrm{D}$ binding studies on MHCII-expressing cells and lipid bilayer-anchored extracellular domains of CD4 (as well as of CD2 to allow cell adhesion). In agreement with the adhesion studies (86), this binding is specific because the MHCII non-expressing cells did not bind to CD4 on supported planar bilayers (75). CD4 very weakly bound to MHCII (approaching the detection limit of the method) according to an adhesion frequency assay with micropipette-attached interacting cells (77). Therefore, it is unclear how CD4 facilitates adhesion between coreceptor- and MHCII-expressing cells.

The way to explain the ability of CD4-MHCII interaction to facilitate both cell-to-cell adhesion and the antigen-independent accumulation of coreceptors at contact sites with MHCIIexpressing cells can be the organization of these molecules in higher-order structures. Multimerization enhances the avidity of the TCR-MHC interaction (89-91). Similarly, the multivalent interaction of CD4 and its ligand can provide this interaction with the appropriate strength. In this direction, it was suggested that palmitoylation targets CD4 to membrane lipid domains, called lipid rafts (55). Because the support for the existence of these domains in living cells remains inconclusive $(92,93)$, future studies must determine whether CD4 is associated with such entities and, if so, with what kinetics. Alternatively, CD4 can form large oligomers in unstimulated $\mathrm{T}$ cells (94). These oligomers must be disassembled upon stimulation because it is unlikely that such large structures are associated with the TCR/CD3 complex or with TCR microclusters. CD4 associates closely ( $<5 \mathrm{~nm}$ distance, as determined by Forster resonance energy transfer, FRET) with the TCR/pMHC complex upon stimulation $(68,71,79)$. Whereas, biochemical and functional data indicate the existence of $\mathrm{CD} 4$ dimers (or higher order oligomers) in unstimulated T cells $(94,95)$, direct observations of fixed or living cells using FRET has provided conflicting data $(57,96,97)$. In these studies, FRET values are very low compared to the dimeric controls, which indicates either that only a small fraction of CD4 is oligomeric or that these structures are highly unstable. Moreover, the FRET-based characterization of CD4 oligomers may suffer from the limitations of this method which cannot distinguish between clustered molecules and oligomers, except only when a protein is assembled in a stable structure and when the appropriate data analysis methods are used (98). Such conditions have not yet been applied in studies of CD4 oligomerization. Thus, direct proof of CD4 oligomerization in living cells is still missing.

Another possible way to increase availability of CD4 for multivalent interactions is the formation of molecular clusters with a high density of coreceptors. Such CD4 nanoclusters exist in both unstimulated and stimulated murine T-cell blasts (99) and unstimulated Jurkat T cells (100). We also previously found that clustering depends on the presence of intact CD4 extracellular domains and palmitoylation sites (100). Clustering in nanoscopic structures (average diameter of $\sim 100 \mathrm{~nm}$ ) allows for multivalent ligand binding and frequent rebinding (29), which can provide the CD4-MHC interaction with sufficient strength to stabilize the sites of the contact between CD4- and MHCII-expressing cells $(86,87)$. Shapes and molecular densities of CD4 clusters $(99,100)$ are similar to those of TCR and associated effector signaling molecules $(25,101)$. On the other hand, the 2D character of the applied analytical methods does not provide a full understanding of these structures.

More recently, TCRs and their effector molecules were found to accumulate in the tips of membrane protrusions that are reminiscent of microvilli $(102,103)$. Microvilli are finger-like plasma membrane protrusions with diameter $\sim 100 \mathrm{~nm}$; they are formed by cross-linked actin bundles that are tightly associated with membranes (Figure 4A). In sensory cells (e.g., hairy cells) or intestinal epithelial cells, these structures form extensive cell surfaces and accumulate selected receptors on their tips. The functions of microvilli in lymphocytes (Figure 4B) are less understood. Using scanning electron microscopy, microvilli were found to form primary contact sites with antigen-presenting dendritic cells $(104,105)$. The molecular details of this interaction have remained unknown until very recently (103). CD4 also accumulates in the microvilli of cultured $\mathrm{T}$ cells in a process that is regulated by the coreceptor association with Lck (106, 107). It is, therefore, possible that CD4 nanoclusters are indeed molecular assemblies of the coreceptor on the tips of the microvilli (Figure 4C). CD4 accumulation in the tips of the microvilli could explain its ability to facilitate adhesion between $\mathrm{T}$ cells and MHCII-positive cells.

Microvilli on dendritic cells interact with their counterparts on $\mathrm{T}$ cells during the antigen recognition (105). Biochemical and preliminary microscopy data indicate that MHCII accumulates in specialized membrane domains in a process that is regulated by members of the tetraspanins family, CD9 and CD63 (108-110). Tetraspanins CD9 and CD53 modulate the size and frequency of microvilli in leukocytes and epithelial cells $(104,111)$. However, it is unclear whether tetraspanins can enhance the sorting of MHCII to the tips of the microvilli; in addition, the organization of these structures on APCs must be characterized in the future.

\section{CONCLUSIONS AND FUTURE PERSPECTIVES}

The results of 30 years of research indicate that CD4 has a dual function in peripheral $\mathrm{T}$ cells (and potentially in thymocytes). Firstly, it interacts with its ligand in an antigen-independent manner so as to induce contact between T cells and MHCIIexpressing cells (Model 3; Figure 3). Second, CD4 interacts with pMHCII-TCR in an antigen-dependent manner so as to deliver Lck kinase to the complex and thus enhance $\mathrm{T}$ cell sensitivity (Model 2). These two roles of CD4 do not have to be mutually exclusive. A direct role of $\mathrm{CD} 4$ in stabilizing 


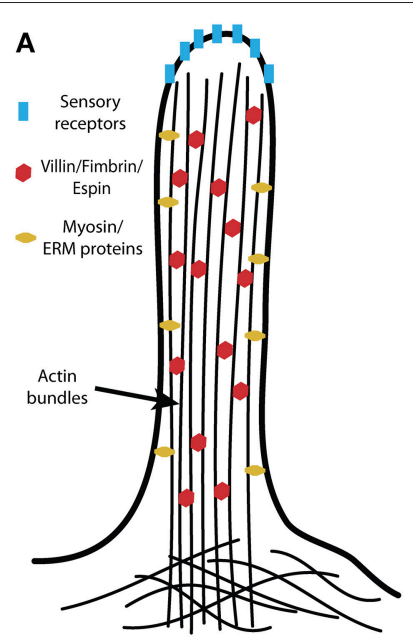

B
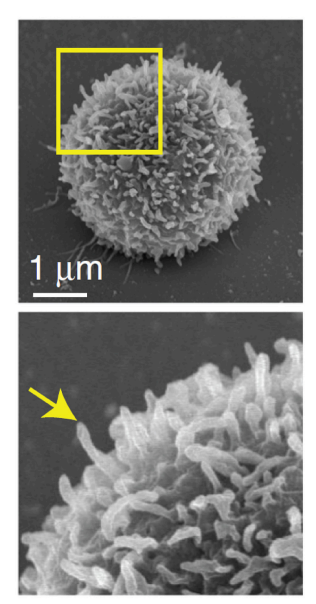

C
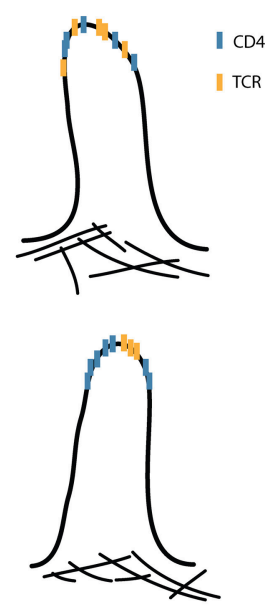

FIGURE 4 | Microvilli in T-cell activation. (A) A schematic illustration of a microvillus with villin, fimbrin and espin internally cross-linking compact actin bundles, which tightly fill the microvilli. The plasma membrane is also closely associated with the actin bundles via the ezrin, redoxin, and moesin (ERM) proteins; the dynamics of microvilli involve specialized myosins. The tips of the sensory (i.e., hairy) cell microvilli accumulate critical receptors. (B) The peripheral T cells are covered by finger-like protrusions that are reminiscent of microvilli on sensory cells. (C) Molecular organization of CD4 with respect to other T-cell signaling molecules (e.g., TCR) on microvilli remains unknown. These molecules may be randomly distributed (upper panel) or assembled into specific domains (lower panel). (B) Is adapted from Kim et al. (104) licensed under Creative Commons (CC BY 4.0).

the TCR-pMHCII interaction (Model 1) is not accepted any longer (62).

The antigen-independent function of CD4 is less understood. Its localization to microvilli (106) - as well as the evidence that the microvilli are the primary contacts between $\mathrm{T}$ cells and APCs (103-105) - indicates that CD4 can function as a scanning machinery, thus allowing $\mathrm{T}$ cells to select for cells that have MHCII on their surface. This may help to target TCRs toward the places with the highest MHC density and thus avoid interactions with cells that lack the ligand. The nanoscopic $3 \mathrm{D}$ organization of $\mathrm{MHCII}$ on APCs remains unknown. A full molecular anatomy of a synaptic vesicle (which was purified from neurons) indicates extreme protein density and reveals specific functional distribution of molecules in these structures (112). We believe that the creation of a similar model of microvillar tips on $\mathrm{T}$ cells and APCs will help to answer several intriguing questions regarding the initial phase of T-cell activation.

Importantly, the contact sites formed between $\mathrm{T}$ cells and APCs should also be explored using super-resolution techniques that have recently been adapted for living cells, including stimulated emission depletion (STED), super-resolution optical fluctuation imaging (SOFI) and lattice light sheet microscopy $(103,113,114)$. Such studies are needed to confirm whether microvilli dominate the T cell-APC contact site and to determine the function of microvilli in T-cell activation. Other forms of membrane protrusions, such as filopodia and membrane ruffles, may also participate in this process. If CD4 scans the surface of the surrounding cells for MHCII-rich areas, it will be very important to determine whether such interactions stimulate changes in the T-cell membrane topology or molecular architecture of $\mathrm{T}$ cell microvilli, as has been observed in mechanosensory cells (115). Such changes may predetermine the local environment that TCRs require for rapid but highly selective antigen-induced signaling.

CD4 is one of the most studied molecules in the human body. This is mainly because it facilitates the infection of $\mathrm{T}$ cells with HIV-1. On the other hand, its function in various subsets of peripheral $\mathrm{T}$ cells remains poorly understood. New technologies that enable high-detail imaging of cellular structures provide previously unexplored ways to resolve such long-neglected topics. Using these techniques can lead to a better understanding of multifaceted role of CD4 in peripheral $\mathrm{T}$ cells and, potentially, in other CD4-expressing cells.

\section{AUTHOR CONTRIBUTIONS}

All authors listed have made a substantial, direct and intellectual contribution to the work, and approved it for publication.

\section{FUNDING}

The Czech Science Foundation funded this work (19-07043S).

\section{ACKNOWLEDGMENTS}

We would like to thank Silke Kerruth for providing a critical reading of the manuscript. 


\section{REFERENCES}

1. Garcillan B, Marin AV, Jimenez-Reinoso A, Briones AC, Munoz-Ruiz M, Garcia-Leon MJ, et al. gammadelta T Lymphocytes in the diagnosis of human T cell receptor immunodeficiencies. Front Immunol. (2015) 6:20. doi: 10. 3389/fimmu.2015.00020

2. Chakraborty AK, Weiss A. Insights into the initiation of TCR signaling. Nat Immunol. (2014) 15:798-807. doi: 10.1038/ni.2940

3. Lo WL, Shah NH, Ahsan N, Horkova V, Stepanek O, Salomon AR, et al. Lck promotes Zap70-dependent LAT phosphorylation by bridging Zap70 to LAT. Nat Immunol. (2018) 19:733-41. doi: 10.1038/s41590-0180131-1

4. Malissen B, Aguado E, Malissen M. Role of the LAT adaptor in Tcell development and Th2 differentiation. Adv Immunol. (2005) 87:1-25. doi: 10.1016/S0065-2776(05)87001-4

5. Courtney AH, Lo WL, Weiss A. TCR Signaling: mechanisms of initiation and propagation. Trends Biochem Sci. (2018) 43:108-23. doi: 10.1016/j.tibs.2017.11.008

6. Van Laethem F, Sarafova SD, Park JH, Tai X, Pobezinsky L, Guinter TI, et al. Deletion of CD4 and CD8 coreceptors permits generation of alphabetaT cells that recognize antigens independently of the MHC. Immunity. (2007) 27:735-50. doi: 10.1016/j.immuni.2007.10.007

7. Ballek O, Valecka J, Manning J, Filipp D. The pool of preactivated Lck in the initiation of T-cell signaling: a critical re-evaluation of the Lck standby model. Immunol Cell Biol. (2015) 93:384-95. doi: 10.1038/icb.2014.100

8. Dustin ML, Bromley SK, Kan Z, Peterson DA, Unanue ER. Antigen receptor engagement delivers a stop signal to migrating T lymphocytes. Proc Natl Acad Sci USA. (1997) 94:3909-13. doi: 10.1073/pnas.94.8.3909

9. Drbal K, Angelisova P, Cerny J, Pavlistova D, Cebecauer M, Novak P, et al. Human leukocytes contain a large pool of free forms of CD18. Biochem Biophys Res Commu. (2000) 275:295-9. doi: 10.1006/bbrc.2000.3299

10. Monks CR, Freiberg BA, Kupfer H, Sciaky N, Kupfer A. Three-dimensional segregation of supramolecular activation clusters in T cells. Nature. (1998) 395:82-6. doi: 10.1038/25764

11. Grakoui A, Bromley SK, Sumen C, Davis MM, Shaw AS, Allen PM, et al. The immunological synapse: a molecular machine controlling $\mathrm{T}$ cell activation. Science. (1999) 285:221-7. doi: 10.1126/science.285.5425.221

12. Dustin ML, Tseng SY, Varma R, Campi G. T cell-dendritic cell immunological synapses. Curr Opin Immunol. (2006) 18:512-6. doi: 10.1016/j.coi.2006.05.017

13. Brossard C, Feuillet V, Schmitt A, Randriamampita C, Romao M, Raposo G, et al. Multifocal structure of the T cell - dendritic cell synapse. Eur J Immunol. (2005) 35:1741-53. doi: 10.1002/eji.200425857

14. Mempel TR, Henrickson SE, Von Andrian UH. T-cell priming by dendritic cells in lymph nodes occurs in three distinct phases. Nature. (2004) 427:1549. doi: 10.1038/nature02238

15. Varma R, Campi G, Yokosuka T, Saito T, Dustin ML. T cell receptorproximal signals are sustained in peripheral microclusters and terminated in the central supramolecular activation cluster. Immunity. (2006) 25:117-27. doi: 10.1016/j.immuni.2006.04.010

16. Friedman RS, Beemiller P, Sorensen CM, Jacobelli J, Krummel MF. (2010). Real-time analysis of $\mathrm{T}$ cell receptors in naive cells in vitro and in vivo reveals flexibility in synapse and signaling dynamics. J Exp Med. 207:2733-49. doi: 10.1084/jem.20091201

17. Moreau HD, Lemaitre F, Garrod KR, Garcia Z, Lennon-Dumenil AM, Bousso P. Signal strength regulates antigen-mediated T-cell deceleration by distinct mechanisms to promote local exploration or arrest. Proc Natl Acad Sci USA. (2015) 112:12151-6. doi: 10.1073/pnas.1506654112

18. Dustin ML. Cell adhesion molecules and actin cytoskeleton at immune synapses and kinapses. Curr Opin Cell Biol. (2007) 19:529-33. doi: $10.1016 /$ j.ceb.2007.08.003

19. Mayya V, Judokusumo E, Abu Shah E, Peel CG, Neiswanger W, Depoil $\mathrm{D}$, et al. Durable Interactions of $\mathrm{T}$ Cells with $\mathrm{T}$ cell receptor stimuli in the absence of a stable immunological synapse. Cell Rep. (2018) 22:340-9. doi: 10.1016/j.celrep.2017.12.052

20. Dustin ML. Supported bilayers at the vanguard of immune cell activation studies. J Struct Biol. (2009) 168:152-60. doi: 10.1016/j.jsb.2009. 05.007
21. Owen DM, Gaus K, Magee AI, Cebecauer M. Dynamic organization of lymphocyte plasma membrane: lessons from advanced imaging methods. Immunology. (2010) 131:1-8. doi: 10.1111/j.1365-2567.2010.03319.x

22. Campi G, Varma R, Dustin ML. Actin and agonist MHC-peptide complexdependent $\mathrm{T}$ cell receptor microclusters as scaffolds for signaling. J Exp Med. (2005) 202:1031-6. doi: 10.1084/jem.20051182

23. Yokosuka T, Sakata-Sogawa K, Kobayashi W, Hiroshima M, HashimotoTane A, Tokunaga M, et al. Newly generated T cell receptor microclusters initiate and sustain $\mathrm{T}$ cell activation by recruitment of Zap70 and SLP-76. Nat Immunol. (2005) 6:1253-62. doi: 10.1038/ni1272

24. Hashimoto-Tane A, Sakuma M, Ike H, Yokosuka T, Kimura Y, Ohara O, et al. Micro-adhesion rings surrounding TCR microclusters are essential for T cell activation. J Exp Med. (2016) 213:1609-25. doi: 10.1084/jem.20151088

25. Lillemeier BF, Mortelmaier MA, Forstner MB, Huppa JB, Groves JT, Davis $\mathrm{M}$, et al. TCR and Lat are expressed on separate protein islands on T cell membranes and concatenate during activation. Nat Immunol. (2010) 11:90-6. doi: 10.1038/ni.1832

26. Williamson DJ, Owen DM, Rossy J, Magenau A, Wehrmann M, Gooding JJ, et al. Pre-existing clusters of the adaptor Lat do not participate in early T cell signaling events. Nat Immunol. (2011) 12:655-62. doi: 10.1038/ni.2049

27. Soares H, Henriques R, Sachse M, Ventimiglia L, Alonso MA, Zimmer $\mathrm{C}$, et al. Regulated vesicle fusion generates signaling nanoterritories that control T cell activation at the immunological synapse. J Exp Med. (2013) 210:2415-33. doi: 10.1084/jem.20130150

28. Crites TJ, Padhan K, Muller J, Krogsgaard M, Gudla PR, Lockett SJ, et al. TCR microclusters pre-exist and contain molecules necessary for TCR signal transduction. J Immunol. (2014) 193:56-67. doi: 10.4049/jimmunol.1400315

29. Cebecauer M, Spitaler M, Serge A, Magee AI. Signalling complexes and clusters: functional advantages and methodological hurdles. J Cell Sci. (2010) 123:309-20. doi: 10.1242/jcs.061739

30. Schamel WW, Arechaga I, Risueno RM, van Santen HM, Cabezas P, Risco $\mathrm{C}$, et al. Coexistence of multivalent and monovalent TCRs explains high sensitivity and wide range of response. J Exp Med. (2005) 202:493-503. doi: 10.1084/jem.20042155

31. Kumar R, Ferez M, Swamy M, Arechaga I, Rejas MT, Valpuesta JM, et al. Increased sensitivity of antigen-experienced $\mathrm{T}$ cells through the enrichment of oligomeric T cell receptor complexes. Immunity. (2011) 35:375-87. doi: 10.1016/j.immuni.2011.08.010

32. James JR, McColl J, Oliveira MI, Dunne PD, Huang E, Jansson A, et al. The T cell receptor triggering apparatus is composed of monovalent or monomeric proteins. J Biol Chem. (2011) 286:31993-2001. doi: 10.1074/jbc.M111.219212

33. Brameshuber M, Kellner F, Rossboth BK, Ta H, Alge K, Sevcsik E, et al. Monomeric TCRs drive T cell antigen recognition. Nat Immunol. (2018) 19:487-96. doi: 10.1038/s41590-018-0092-4

34. Rossboth B, Arnold AM, Ta H, Platzer R, Kellner F, Huppa JB, et al. TCRs are randomly distributed on the plasma membrane of resting antigen-experienced T cells. Nat Immunol. (2018) 19:821-7. doi: 10.1038/s41590-018-0162-7

35. Huse M, Klein LO, Girvin AT, Faraj JM, Li QJ, Kuhns MS, et al. Spatial and temporal dynamics of $\mathrm{T}$ cell receptor signaling with a photoactivatable agonist. Immunity. (2007) 27:76-88. doi: 10.1016/j.immuni.2007.05.017

36. Trickett A, Kwan YL. T cell stimulation and expansion using anti-CD3/CD28 beads. J Immunol Methods. (2003) 275:251-5. doi: 10.1016/S0022-1759(03)00010-3

37. Van Laethem F, Tikhonova AN, Pobezinsky LA, Tai X, Kimura MY, Le Saout C, et al. Lck availability during thymic selection determines the recognition specificity of the $\mathrm{T}$ cell repertoire. Cell. (2013) 154:1326-41. doi: 10.1016/j.cell.2013.08.009

38. Pennock ND, White JT, Cross EW, Cheney EE, Tamburini BA, Kedl R, et al. T cell responses: naive to memory and everything in between. Adv Physiol Educ. (2013) 37:273-83. doi: 10.1152/advan.00066.2013

39. Itoh Y, Wang Z, Ishida H, Eichelberg K, Fujimoto N, Makino J, et al. Decreased CD4 expression by polarized T helper 2 cells contributes to suboptimal TCR-induced phosphorylation and reduced Ca2 + signaling. Eur J Immunol. (2005) 35:3187-95. doi: 10.1002/eji.200526064

40. Cole DK, Laugel B, Clement M, Price DA, Wooldridge L, Sewell A, et al. The molecular determinants of CD8 co-receptor function. Immunology. (2012) 137:139-48. doi: 10.1111/j.1365-2567.2012.03625.x 
41. Nakayama K, Nakayama K, Negishi I, Kuida K, Louie MC, Kanagawa O, et al. Requirement for CD8 beta chain in positive selection of CD8-lineage T cells. Science. (1994) 263:1131-3. doi: 10.1126/science.8108731

42. Gibbings DJ, Marcet-Palacios M, Sekar Y, Ng MC, Befus AD. CD8 alpha is expressed by human monocytes and enhances Fc gamma R-dependent responses. BMC Immunol. (2007) 8:12. doi: 10.1186/1471-2172-8-12

43. Schuster P, Thomann S, Werner M, Vollmer J, Schmidt B. A subset of human plasmacytoid dendritic cells expresses CD8alpha upon exposure to herpes simplex virus type 1. Front Microbiol. (2015) 6:557. doi: 10.3389/fmicb.2015.00557

44. Gangadharan D, Cheroutre H. The CD8 isoform CD8alphaalpha is not a functional homologue of the TCR co-receptor CD8alphabeta. Curr Opin Immunol. (2004) 16:264-70. doi: 10.1016/j.coi.2004.03.015

45. Arcaro A, Gregoire C, Boucheron N, Stotz S, Palmer E, Malissen B, et al. Essential role of CD8 palmitoylation in CD8 coreceptor function. J Immunol. (2000) 165:2068-76. doi: 10.4049/jimmunol.165.4.2068

46. Janeway, C. A. Jr. The $\mathrm{T}$ cell receptor as a multicomponent signalling machine: CD4/CD8 coreceptors and CD45 in T cell activation. Annu Rev Immunol. (1992) 10:645-74. doi: 10.1146/annurev.iy.10.040192.003241

47. Lin H, Hutchcroft JE, Andoniou CE, Kamoun M, Band H, Bierer B, et al. Association of p59(fyn) with the T lymphocyte costimulatory receptor CD2. Binding of the Fyn Src homology (SH) 3 domain is regulated by the Fyn SH2 domain. J Biol Chem. (1998) 273:19914-21. doi: 10.1074/jbc.273.31.19914

48. Kim PW, Sun ZY, Blacklow SC, Wagner G, Eck MJ. A zinc clasp structure tethers Lck to T cell coreceptors CD4 and CD8. Science. (2003) 301:1725-8. doi: 10.1126/science. 1085643

49. Crise B, Rose JK. Identification of palmitoylation sites on CD4, the human immunodeficiency virus receptor. J Biol Chem. (1992) 267:13593-7.

50. Konig R, Huang LY, Germain RN. MHC class II interaction with CD4 mediated by a region analogous to the MHC class I binding site for CD8. Nature. (1992) 356:796-8. doi: 10.1038/356796a0

51. Yin Y, Wang XX, Mariuzza RA. Crystal structure of a complete ternary complex of T-cell receptor, peptide-MHC, and CD4. Proc Natl Acad Sci USA. (2012) 109:5405-10. doi: 10.1073/pnas.1118801109

52. Wang J-H, Meijers R, Xiong Y, Liu J-H, Sakihama T, Zhang R, et al. Crystal structure of the human CD4 N-terminal two-domain fragment complexed to a class II MHC molecule. PNAS. (2001) 98:10799-804. doi: 10.1073/pnas.191124098

53. Wilen CB, Tilton JC, Doms RW. HIV: cell binding and entry. Cold Spring Harb Perspect Med. (2012) 2:a006866. doi: 10.1101/cshperspect.a006866

54. Richmond J, Tuzova M, Cruikshank W, Center D. Regulation of cellular processes by interleukin-16 in homeostasis and cancer. J Cell Physiol. (2014) 229:139-47. doi: 10.1002/jcp.24441

55. Balamuth F, Brogdon JL, Bottomly K. CD4 raft association and signaling regulate molecular clustering at the immunological synapse site. J Immunol. (2004) 172:5887-92. doi: 10.4049/jimmunol.172.10.5887

56. Cymer F, Veerappan A, Schneider D. Transmembrane helix-helix interactions are modulated by the sequence context and by lipid bilayer properties. Biochim Biophys Acta. (2012) 1818:963-73. doi: 10.1016/j.bbamem.2011.07.035

57. Parrish HL, Glassman CR, Keenen MM, Deshpande NR, Bronnimann MP, Kuhns M, et al. A transmembrane domain GGxxG motif in CD4 contributes to Its Lck-independent function but does not mediate CD4 dimerization. PLoS ONE. (2015) 10:e0132333. doi: 10.1371/journal.pone. 0132333

58. Bernstein HB, Plasterer MC, Schiff SE, Kitchen CM, Kitchen S, Zack J, et al. CD4 expression on activated NK cells: ligation of CD4 induces cytokine expression and cell migration. J Immunol. (2006) 177:3669-76. doi: 10.4049/jimmunol.177.6.3669

59. Zhen A, Krutzik SR, Levin BR, Kasparian S, Zack JA, Kitchen S, et al. CD4 ligation on human blood monocytes triggers macrophage differentiation and enhances HIV infection. J Virol. (2014) 88:9934-46. doi: 10.1128/JVI.00616-14

60. Straus DB, Weiss A. Genetic evidence for the involvement of the lck tyrosine kinase in signal transduction through the T cell antigen receptor. Cell. (1992) 70:585-93. doi: 10.1016/0092-8674(92)90428-F

61. Straus DB, Weiss A. The CD3 chains of the $T$ cell antigen receptor associate with the ZAP-70 tyrosine kinase and are tyrosine phosphorylated after receptor stimulation. J Exp Med. (1993) 178:1523-30. doi: 10.1084/jem.178.5.1523

62. Artyomov MN, Lis M, Devadas S, Davis MM, Chakraborty AK. CD4 and CD8 binding to MHC molecules primarily acts to enhance Lck delivery. Proc Natl Acad Sci U S A. (2010) 107:16916-21. doi: 10.1073/pnas.1010568107

63. van der Merwe PA, Dushek O. Mechanisms for T cell receptor triggering. Nat Rev Immunol. (2011) 11:47-55. doi: 10.1038/nri2887

64. Marrack P, Endres R, Shimonkevitz R, Zlotnik A, Dialynas D, Fitch F, et al. The major histocompatibility complex-restricted antigen receptor on T cells. II. Role of the L3T4 product. J Exp Med. (1983) 158:1077-91. doi: 10.1084/jem.158.4.1077

65. Hampl J, Chien YH, Davis MM. CD4 augments the response of a T cell to agonist but not to antagonist ligands. Immunity. (1997) 7:379-85 doi: 10.1016/S1074-7613(00)80359-3

66. Janeway CA, Chervonsky AV, Sant'Angelo D. T-cell receptors: is the repertoire inherently MHC-specific? Curr Biol. (1997) 7:R299-300. doi: 10.1016/S0960-9822(06)00142-4

67. Madrenas J, Chau LA, Smith J, Bluestone JA, Germain RN. The efficiency of CD4 recruitment to ligand-engaged TCR controls the agonist/partial agonist properties of peptide-MHC molecule ligands. Journal of Experimental Medicine. (1997) 185:219-29. doi: 10.1084/jem.185.2.219

68. Li QJ, Dinner AR, Qi S, Irvine DJ, Huppa JB, Davis MM, et al. CD4 enhances $\mathrm{T}$ cell sensitivity to antigen by coordinating Lck accumulation at the immunological synapse. Nat Immunol. (2004) 5:791-9. doi: 10.1038/ni1095

69. Li Y, Yin Y, Mariuzza RA. Structural and biophysical insights into the role of CD4 and CD8 in T cell activation. Front Immunol. (2013) 4:206. doi: 10.3389/fimmu.2013.00206

70. Irvine DJ, Purbhoo MA, Krogsgaard M, Davis MM. Direct observation of ligand recognition by T cells. Nature. (2002) 419:845-9. doi: $10.1038 /$ nature 01076

71. Krogsgaard M, Li QJ, Sumen C, Huppa JB, Huse M, Davis M, et al Agonist/endogenous peptide-MHC heterodimers drive T cell activation and sensitivity. Nature. (2005) 434:238-43. doi: 10.1038/nature03391

72. Bozzacco L, Yu H, Zebroski HA, Dengjel J, Deng H, Mojsov S, et al. Mass spectrometry analysis and quantitation of peptides presented on the MHC II molecules of mouse spleen dendritic cells. J Proteome Res. (2011) 10:5016-30. doi: $10.1021 / \mathrm{pr} 200503 \mathrm{~g}$

73. Birnbaum ME, Mendoza JL, Sethi DK, Dong S, Glanville J, Dobbins J, et al. Deconstructing the peptide-MHC specificity of T cell recognition. Cell. (2014) 157:1073-87. doi: 10.1016/j.cell.2014.03.047

74. Sibener LV, Fernandes RA, Kolawole EM, Carbone CB, Liu F, McAffee $\mathrm{D}$, et al. Isolation of a structural mechanism for uncoupling $\mathrm{T}$ cell receptor signaling from peptide-MHC binding. Cell. (2018) 174:672-87 e627. doi: 10.1016/j.cell.2018.06.017

75. Jonsson P, Southcombe JH, Santos AM, Huo J, Fernandes RA, McColl J, et al. Remarkably low affinity of CD4/peptide-major histocompatibility complex class II protein interactions. Proc Natl Acad Sci U S A. (2016) 113:5682-7. doi: $10.1073 /$ pnas.1513918113

76. Huppa JB, Axmann M, Mortelmaier MA, Lillemeier BF, Newell EW, Brameshuber $\mathrm{M}$, et al. TCR-peptide-MHC interactions in situ show accelerated kinetics and increased affinity. Nature. (2010) 463:963-7. doi: 10.1038 /nature08746

77. Hong J, Persaud SP, Horvath S, Allen PM, Evavold BD, Zhu C. Force-regulated in situ TCR-peptide-bound MHC class II kinetics determine functions of CD4+ T cells. J Immunol. (2015) 195:3557-64. doi: 10.4049/jimmunol.1501407

78. Krummel MF. Differential clustering of CD4 and CD3zeta During $\mathrm{T}$ cell recognition. Science. (2000) 289:1349-52. doi: 10.1126/science.289.5483.1349

79. Zal T, Zal MA, Gascoigne NR. Inhibition of $\mathrm{T}$ cell receptor-coreceptor interactions by antagonist ligands visualized by live FRET imaging of the T-hybridoma immunological synapse. Immunity. (2002) 16:521-34 doi: 10.1016/S1074-7613(02)00301-1

80. Kao H, Lin J, Littman DR, Shaw AS, Allen PM. Regulated movement of CD4 in and out of the immunological synapse. J Immunol. (2008) 181:8248-57. doi: 10.4049/jimmunol.181.12.8248

81. Glassman CR, Parrish HL, Deshpande NR, Kuhns MS. The CD4 and CD3deltaepsilon Cytosolic Juxtamembrane Regions Are Proximal within 
a Compact TCR-CD3-pMHC-CD4 Macrocomplex. J Immunol. (2016) 196:4713-22. doi: 10.4049/jimmunol.1502110

82. Veillette A, Bookman MA, Horak EM, Bolen JB. The CD4 and CD8 T-cell surface-antigens are associated with the internal membrane tyrosine-protein kinase P56LCK. Cell. (1988) 55:301-8. doi: 10.1016/0092-8674(88)90053-0

83. Holdorf AD, Lee KH, Burack WR, Allen PM, Shaw AS. Regulation of Lck activity by $\mathrm{CD} 4$ and $\mathrm{CD} 28$ in the immunological synapse. Nat Immunol. (2002) 3:259-64 doi: 10.1038/ni761

84. Danielian S, Fagard R, Alcover A, Acuto O, Fischer S. The lymphocytespecific protein tyrosine kinase p56lck is hyperphosphorylated on serine and tyrosine residues within minutes after activation via $\mathrm{T}$ cell receptor or CD2. Eur J Immunol. (1989) 19:2183-9. doi: 10.1002/eji.1830191202

85. Soula M, Rothhut B, Camoin L, Guillaume JL, Strosberg D, Vorherr T, et al. Anti-CD3 and phorbol ester induce distinct phosphorylated sites in the SH2 domain of p56lck. J Biol Chem. (1993) 268:27420-7.

86. Doyle C, Strominger JL. Interaction between CD4 and class II MHC molecules mediates cell adhesion. Nature. (1987) 330:256-9. doi: $10.1038 / 330256 \mathrm{a} 0$

87. Kinch MS, Strominger JL, Doyle C. Cell-adhesion mediated by $\mathrm{Cd} 4$ and Mhc class-Ii proteins requires active cellular processes. I Immunol. (1993) 151:4552-61.

88. Hoerter JA, Brzostek J, Artyomov MN, Abel SM, Casas J, Rybakin V, et al. Coreceptor affinity for MHC defines peptide specificity requirements for TCR interaction with coagonist peptide-MHC. J Exp Med. (2013) 210:180721. doi: 10.1084/jem.20122528

89. Altman JD, Moss PAH, Goulder PJR, Barouch DH, McHeyzer-Williams MG, Bell JI, et al. Phenotypic analysis of antigen-specific T lymphocytes. Science. (1996) 274:94-6. doi: 10.1126/science.274.5284.94

90. Cochran JR, Cameron TO, Stern LJ. The relationship of MHCpeptide binding and $\mathrm{T}$ cell activation probed using chemically defined MHC class II oligomers. Immunity. (2000) 12:241-50. doi: 10.1016/S1074-7613(00)80177-6

91. Cebecauer M, Guillaume P, Hozak P, Mark S, Everett H, Schneider P, et al. Soluble MHC-peptide complexes induce rapid death of CD8+ CTL. J Immunol. (2005) 174:6809-19. doi: 10.4049/jimmunol.174.11.6809

92. Sevcsik E, Schutz GJ. With or without rafts? alternative views on cell membranes. Bioessays. (2015) 38:129-39. doi: 10.1002/bies.201500150

93. Bernardino de la Serna J, Schutz GJ, Eggeling C, Cebecauer M. There is no simple model of the plasma membrane organization. Front Cell Develop Biol. (2016) 4:106. doi: 10.3389/fcell.2016.00106

94. Sakihama T, Smolyar A, Reinherz EL. Oligomerization of CD4 is required for stable binding to class II major histocompatibility complex proteins but not for interaction with human immunodeficiency virus gp120. Proc Natl Acad Sci USA. (1995) 92:6444-8. doi: 10.1073/pnas.92.14.6444

95. Lynch GW, Sloane AJ, Raso V, Lai A, Cunningham AL. Direct evidence for native CD4 oligomers in lymphoid and monocytoid cells. Eur J Immunol. (1999) 29:2590-602. doi: 10.1002/(SICI)15214141(199908)29:08\&lt;2590::AID-IMMU2590\&gt;3.0.CO;2-R

96. Matthias LJ, Yam PT, Jiang XM, Vandegraaff N, Li P, Poumbourios P, et al. Disulfide exchange in domain 2 of CD4 is required for entry of HIV-1. Nat Immunol. (2002) 3:727-32. doi: 10.1038/ni815

97. Moldovan M-C, Yachou A, Levesque $\mathrm{K}, \mathrm{Wu} \mathrm{H}$, Hendrickson WA, Cohen EA, et al. CD4 dimers constitute the functional component required for $\mathrm{T}$ cell activation. $J$ Immunol. (2002) 169:6261-8. doi: 10.4049/jimmunol.169.11.6261

98. King C, Sarabipour S, Byrne P, Leahy DJ, Hristova K. The FRET signatures of noninteracting proteins in membranes: simulations and experiments. Biophys J. (2014) 106:1309-17. doi: 10.1016/j.bpj.2014.01.039

99. Roh KH, Lillemeier BF, Wang F, Davis MM. The coreceptor CD4 is expressed in distinct nanoclusters and does not colocalize with T-cell receptor and active protein tyrosine kinase p56lck. Proc Natl Acad Sci USA. (2015) 112:E1604-13. doi: 10.1073/pnas.1503532112

100. Lukes T, Glatzova D, Kvicalova Z, Levet F, Benda A, Letschert S, et al. Quantifying protein densities on cell membranes using superresolution optical fluctuation imaging. Nat Commun. (2017) 8:1731. doi: $10.1038 /$ s41467-017-01857-x
101. Rossy J, Owen DM, Williamson DJ, Yang Z, Gaus K. Conformational states of the kinase Lck regulate clustering in early T cell signaling. Nat Immunol. (2013) 14:82-9. doi: 10.1038/ni.2488

102. Jung Y, Riven I, Feigelson SW, Kartvelishvily E, Tohya K, Miyasaka M, et al. Three-dimensional localization of T-cell receptors in relation to microvilli using a combination of superresolution microscopies. Proc Natl Acad Sci USA. (2016) 113:E5916-24. doi: 10.1073/pnas.1605399113

103. Cai E, Marchuk K, Beemiller P, Beppler C, Rubashkin MG, Weaver $\mathrm{VM}$, et al. Visualizing dynamic microvillar search and stabilization during ligand detection by $\mathrm{T}$ cells. Science. (2017) 356:eaal3118. doi: 10.1126/science.aal3118

104. Kim HR, Mun Y, Lee KS, Park YJ, Park JS, Park JH, et al. T cell microvilli constitute immunological synaptosomes that carry messages to antigen-presenting cells. Nat Commun. (2018) 9:3630. doi: 10.1038/s41467-018-06090-8

105. Fisher PJ, Bulur PA, Vuk-Pavlovic S, Prendergast FG, Dietz AB. Dendritic cell microvilli: a novel membrane structure associated with the multifocal synapse and T-cell clustering. Blood. (2008) 112:5037-45. doi: 10.1182/blood-2008-04-149526

106. Foti M, Phelouzat MA, Holm A, Rasmusson BJ, Carpentier JL. p56Lck anchors CD4 to distinct microdomains on microvilli. Proc Natl Acad Sci USA. (2002) 99:2008-13. doi: 10.1073/pnas.042689099

107. Steffens CM, Hope TJ. Localization of CD4 and CCR5 in living cells. J Virol. (2003) 77:4985-91. doi: 10.1128/JVI.77.8.4985-4991.2003

108. Unternaehrer JJ, Chow A, Pypaert M, Inaba K, Mellman I. The tetraspanin CD9 mediates lateral association of MHC class II molecules on the dendritic cell surface. Proc Natl Acad Sci USA. (2007) 104:234-9. doi: 10.1073/pnas.0609665104

109. Khandelwal S, Roche PA. Distinct MHC class II molecules are associated on the dendritic cell surface in cholesterol-dependent membrane microdomains. J Biol Chem. (2010) 285:35303-10. doi: 10.1074/jbc.M110.147793

110. Rocha-Perugini V, Martinez Del Hoyo G, Gonzalez-Granado J. Ramirez-Huesca, MM, Zorita V, Rubinstein E, et al. CD9 Regulates Major Histocompatibility Complex Class II Trafficking in MonocyteDerived Dendritic Cells. Mol Cell Biol. (2017) 37:e00202-17. doi: 10.1128/MCB.00202-17

111. Singethan K, Muller N, Schubert S, Luttge D, Krementsov DN, Khurana SR, et al. CD9 clustering and formation of microvilli zippers between contacting cells regulates virus-induced cell fusion. Traffic. (2008) 9:924-35. doi: $10.1111 /$ j.1600-0854.2008.00737.x

112. Takamori S, Holt M, Stenius K, Lemke EA, Gronborg M, Riedel D, et al. Molecular anatomy of a trafficking organelle. Cell. (2006) 127:831-46. doi: $10.1016 /$ j.cell.2006.10.030

113. Deschout H, Lukes T, Sharipov A, Szlag D, Feletti L, Vandenberg $\mathrm{W}$, et al. Complementarity of PALM and SOFI for super-resolution live-cell imaging of focal adhesions. Nat Commun. (2016) 7:13693. doi: $10.1038 /$ ncomms 13693

114. Fritzsche M, Fernandes RA, Chang VT, Colin-York H, Clausen MP, Felce $\mathrm{JH}$, et al. Cytoskeletal actin dynamics shape a ramifying actin network underpinning immunological synapse formation. Sci Adv. (2017) 3:e1603032. doi: 10.1126/sciadv.1603032

115. Lange K. Fundamental role of microvilli in the main functions of differentiated cells: Outline of an universal regulating and signaling system at the cell periphery. J Cell Physiol. (2011) 226:896-927. doi: 10.1002/jcp.22302

Conflict of Interest Statement: The authors declare that the research was conducted in the absence of any commercial or financial relationships that could be construed as a potential conflict of interest.

Copyright $\odot 2019$ Glatzová and Cebecauer. This is an open-access article distributed under the terms of the Creative Commons Attribution License (CC BY). The use, distribution or reproduction in other forums is permitted, provided the original author(s) and the copyright owner(s) are credited and that the original publication in this journal is cited, in accordance with accepted academic practice. No use, distribution or reproduction is permitted which does not comply with these terms. 